\title{
Frequency Distribution of Hexamethylenetetramine Crystals
}

L. N. Becka

Citation: The Journal of Chemical Physics 37, 431 (1962); doi: 10.1063/1.1701339

View online: https://doi.org/10.1063/1.1701339

View Table of Contents: http://aip.scitation.org/toc/jcp/37/2

Published by the American Institute of Physics 


\title{
Frequency Distribution of Hexamethylenetetramine Crystals
}

\author{
L. N. BEckA* $\dagger$ \\ Physics Division, Atomic Energy of Canada Limited, Chalk River, Ontario, Canada
}

(Received January 18, 1962)

\begin{abstract}
The energy distribution of neutrons inelastically scattered from hexamethylenetetramine powder at $80^{\circ}$ and $300^{\circ} \mathrm{K}$ is given. Features of the scattering curve are described and interpreted in the light of a simple model of the lattice vibration spectrum.
\end{abstract}

$\mathbf{H}^{1}$ EXAMETHYLENETETRAMINE

(hereafter HMT) is an exceptionally suitable substance with which to study the lattice vibrations of molecular crystals. The crystal has cubic symmetry $(\bar{I} 43 m)$ and a very simple structure (one molecule per primitive cell), the molecules of HMT are nearly spherical and there is no phase transition below the melting point (many other crystals of nearly spherical molecules exhibit solid-phase transitions).

A simple model for the vibration spectrum of HMT has been proposed and data dependent on the lattice dynamics have been analyzed in terms of this model. ${ }^{1}$ The data consisted of elastic constants, ${ }^{2}$ Raman spectrum, ${ }^{3}$ entropies, ${ }^{4}$ and temperature variations of meansquare amplitudes of vibration. ${ }^{1}$ The model separates the modes into six external (intermolecular) and sixty internal (intramolecular) modes. The external modes are represented by a triply degenerate optical branch with an Einstein distribution and by an acoustical branch with a Debye distribution. Furthermore, the external optical modes are assumed to be pure librations and the acoustical modes pure translations. The characteristic frequencies of the external optical and acoustical modes $\nu_{E}$ and $\nu_{D}$, respectively, were determined from the amplitudes of vibration at $298^{\circ} \mathrm{K}$ as $h \nu_{D}=9.0$ milli-eV (hereafter meV) $\left(72.6 \mathrm{~cm}^{-1}\right)$ and $h \nu_{E}=5.5 \mathrm{meV}\left(44.4 \mathrm{~cm}^{-1}\right)$. These values agree well with those suggested by the spectroscopic and calorimetric measurements. The calculated entropy function and the predicted temperature dependence of the vibration amplitudes are very close to their empirical values.

Direct information on the frequency distribution has been obtained with neutron inelastic-scattering experiments. Figure 1 shows the intensity vs scatteredneutron-wavelength patterns of HMT powder at $80^{\circ}$ and $300^{\circ} \mathrm{K}$, obtained using the Chalk River rotating

*Visiting National Research Council Fellow from Buenos Aires, Argentina.

† Present address: Department of Inorganic \& Physical Chemistry, Facultad de Ciencias Exactas y Naturales, Peru 222, Buenos Aires, Argentina.

${ }^{1}$ L. N. Becka and D. W. J. Cruickshank (to be published).

${ }^{2}$ S. Haussühl, Acta Cryst. 11, 58 (1958); G. M. Ramachandran and W. A. Wooster, ibid. 4, 431 (1951).

${ }^{3}$ L. Couture-Mathieu, J. P. Mathieu, J. Cremer, and H. Poulet, J. chim. phys. 48, 1 (1951).

${ }^{4}$ Shu-Sing Chang and E. F. Westrum, J. Phys. Chem. 64, crystal spectrometer. ${ }^{5}$ The measurements were made in the symmetrical transmission position at a scattering

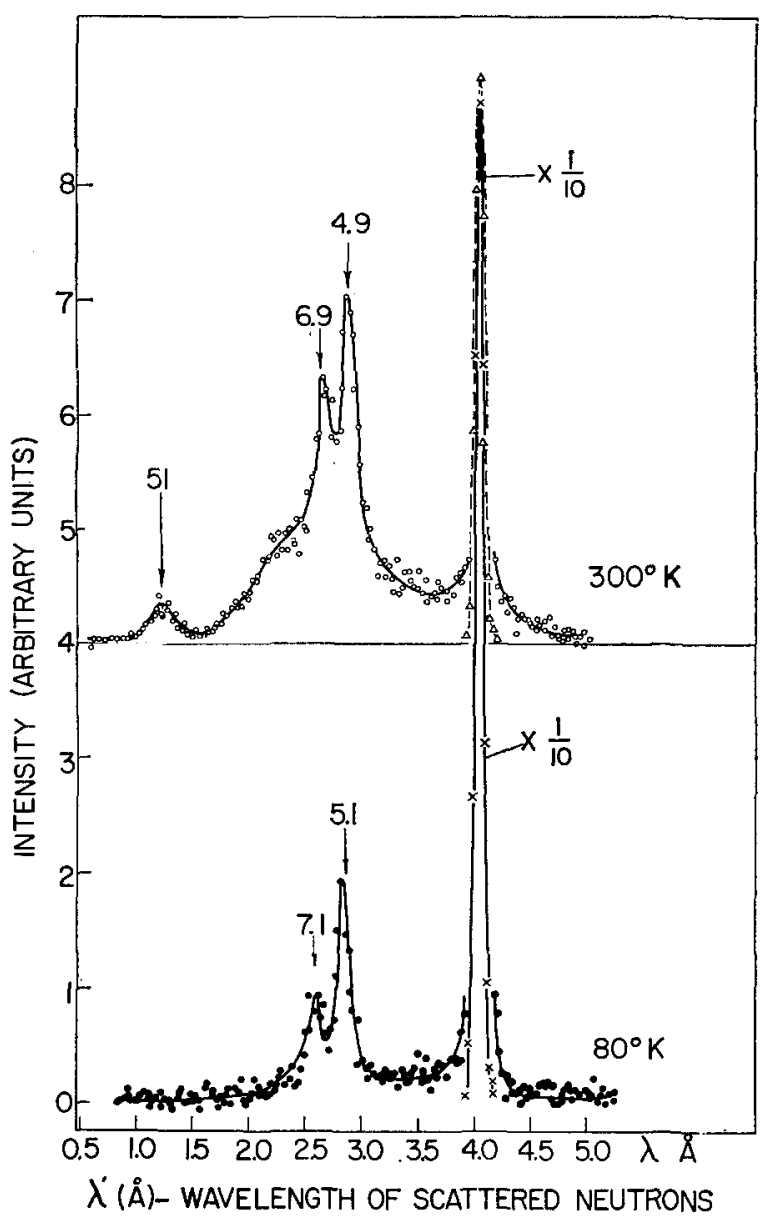

Fig. 1. Plot of intensity vs scattered-neutron wavelength of hexamethylenetetramine powder at $80^{\circ}$ and $300^{\circ} \mathrm{K}$. The positions of the peaks are given in milli electron volts.

angle of 111 degrees with a specimen of $71 \%$ transmission.

The $300^{\circ} \mathrm{K}$ pattern has a very sharp peak at 4.9

6 B. N. Brockhouse, Paper I/S 18, International Atomic Energy Agency Symposium on Inelastic Scattering by Solids and Liquids, Vienna, October 11-14, 1960. Issued as Chalk River Rept. CRNP 947, AECL 1183. 


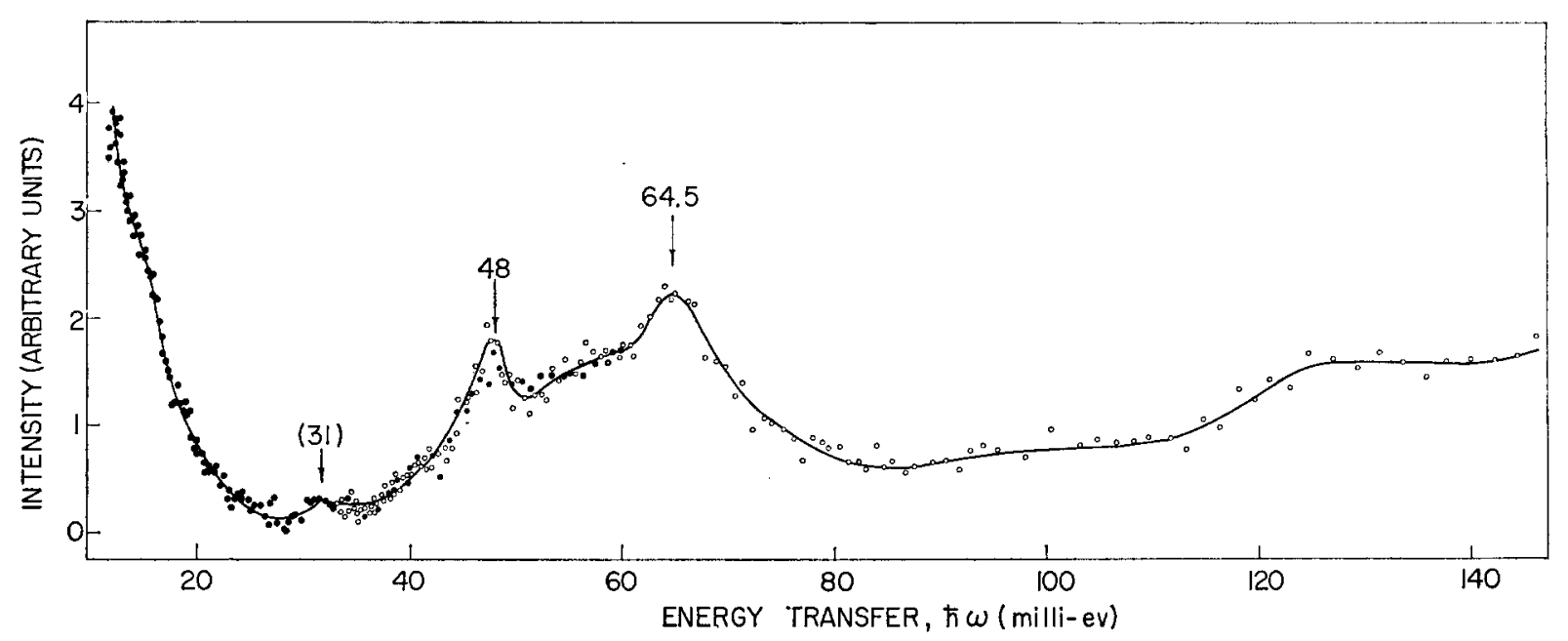

FIG. 2. Plot of intensity vs energy transfer of scattered neutrons of hexamethylenetetramine powder at $300^{\circ} \mathrm{K}$. The positions of the peaks are given in milli electron volts. The small peak at $31 \mathrm{meV}$ appears also with empty sample holder.

$\mathrm{meV}\left(39.5 \mathrm{~cm}^{-1}\right)$ that corresponds very nicely with $h \nu_{E}$; the sharp peak at $6.9 \mathrm{meV}\left(55.7 \mathrm{~cm}^{-1}\right)$ could be due to splitting in the external optical branch or to a very flat acoustical branch; the broad-peaked region underneath the sharp peaks is probably due to the acoustical modes. The peak at $51 \mathrm{meV}\left(411 \mathrm{~cm}^{-1}\right)$ is probably due to some internal modes. The valley between the low-frequency region and the peak at 51 $\mathrm{meV}$ indicates there is little mixing between internal and external modes. The $80^{\circ} \mathrm{K}$ pattern has two sharp peaks at $5.1 \mathrm{meV}\left(41.1 \mathrm{~cm}^{-1}\right)$ and $7.1 \mathrm{meV}(57.3$ $\left.\mathrm{cm}^{-1}\right)$, showing a shift of $+0.2 \mathrm{meV}\left(+1.6 \mathrm{~cm}^{-1}\right)$ in the position of the corresponding peaks at $300^{\circ} \mathrm{K}$. This shift is of the same sign and order of magnitude as the anharmonicity correction to $\nu_{D}$ and $\nu_{E}$ previously assumed ${ }^{1}$ in calculating the entropy function. As expected, higher frequency modes are not excited at $80^{\circ} \mathrm{K}$, and so the intensity falls to zero after the peak at $7.1 \mathrm{meV}$.

Figure 2 shows the intensity vs energy-transfer patterns obtained with $H M T$ powder at $300^{\circ} \mathrm{K}$ using a crystal spectrometer in the beryllium detector method. ${ }^{6}$

${ }^{6}$ A. D. B. Woods, B. N. Brockhouse, M. Sakamoto, and R. N. Sinclair, Paper I/S 22 of I.A.E.A. Symposium (see reference 5). Issued as Chalk River Rept. CRNP 948, AECL 1088.
The peaks at $48 \mathrm{meV}\left(385 \mathrm{~cm}^{-1}\right), 64.5 \mathrm{meV}(520$ $\mathrm{cm}^{-1}$ ), and the region between them correspond well to the lower internal frequencies observed and calculated by Couture-Mathieu $\mathrm{et} \mathrm{al.}{ }^{3}$ [the lowest internal mode has a calculated $h \nu=43 \pm 5 \mathrm{meV} \quad(347 \pm 40$ $\mathrm{cm}^{-1}$ ), and is inactive in Raman and infrared]. Again it is seen that there are no normal modes in the frequency region between the internal and external modes.

Discrepancies between the observed frequency distribution and that predicted by the simple model are evident in the high cutoff of the acoustical spectrum and in the existence of two sharp peaks instead of just one. The model is inadequate for reproducing the actual distribution, but very good for evaluating properties depending on integration over the frequency distribution.

\section{ACKNOWLEDGMENTS}

I am grateful to Dr. D. W. J. Cruickshank for starting me on the studies from which this work developed. I am indebted to Dr. B. N. Brockhouse for his interest and many helpful suggestions. I would like to thank the National Research Council of Canada for the award of a Fellowship. 